\title{
Monitoring Kualitas Air pada Budidaya Hidroganik Berbasis Arduino
}

\author{
Eko Budihartono*1, Yerry Febrian Sabanise $^{2}$, Arif Rakhman ${ }^{3}$ \\ Email: ${ }^{1}$ tara.niscita@gmail.com, ${ }^{2}$ yerryfebrian@gmail.com, ${ }^{3}$ cakrakirana7@gmail.com \\ Prodi DII Teknik Komputer Politernik Harapan Bersama
}

\begin{abstract}
Abstrak
Teknologi hidroganik adalah sistem budidaya yang memadukan sistem hidroponik dan tanpa bahan kimia (organik). Perpaduan keduanya menghasilkan suatu sistem di mana budidaya tanaman dilakukan tanpa media tanah dan menggunakan pupuk organik alami yang berasal dari hewan, umumnya dari kotoran ikan yang mengalir bersamaan dengan aliran air kolam melalui pipa-pipa, bisa juga ditambahkan dengan pupuk kompos atau pupuk kandang. Teknologi ini sering disebut juga sebagai aquaponik, yaitu sistem yang menggabungkan hidroponik dengan kolam budidaya ikan di bawahnya. Setelah bahan siap, petani mengisi kolam dengan ikan, biarkan selama seminggu. Dilanjutkan dengan membibitkan tanaman langsung di media tanam atau di tempat terpisah. Mengingat betapa pentingnya air bagi budidaya tanaman dan ikan maka kualitas air harus tetap terjaga dan dipertahankan kualitasnya Untuk menjaga kualitas air maka diperlukan sebuah alat yang dapat memantau kualitas air tersebut menggunakan Arduino Uno R3 agar dalam budidaya hidroganik tetap terjaga dengan baik. Hal ini disebabkan karena adanya catatan merugikan yang disebabkan oleh aktivitas bawah air dan kualitas air tidak terpantau secara realtime yang datang tibatiba mengakibatkan kerugian pada budidaya hidroganik. Dari tingginya kerugian yang ditimbulkan maka sistem yang dapat memantau kualitas air pada budidaya hidroganik sangat dibutuhkan oleh masyarakat, serta dengan adanya sistem pemantauan kualitas air budidaya hidroganik dapat diperoleh data yang akurat dengan mudah. Aplikasi alat ini dapat memonitoring kualitas air secara otomatis. Parameter dalam pemantauan kualitas air (suhu air, $\mathrm{pH}$ air dan kekeruhan) sehingga dapat dimonitoring kualitas air dalam budidaya hidroganik secara akurat dan hasil yang didapatkan semakin baik.
\end{abstract}

Kata kunci: Arduino Uno, Sensor Suhu, Sensor pH, Sensor Turbidity, LCD, Hidroganik

\section{Pendahuluan}

Air mempunyai peranan yang sangat penting bagi kehidupan pertanian dan perikanan, bahkan air menjadi tumpuan masyarakat untuk membudidayakan hidroganik guna menjadi sumber pangan masyarakat seperti sebagai budidaya sayur-sayuran dan ikan nila diperlukan sebagai kebutuhan masyarakat pada umumnya. Mengingat betapa pentingnya air bagi budidaya tanaman dan ikan nila maka kualitas air harus tetap terjaga dan dipertahankan kualitasnya, lepas dari amoniak dan bebas dari zat asam dan basa agar tidak dapat merusak kualitas air. Untuk menjaga kualitas air di maka diperlukan sebuah alat yang dapat memantau kualitas air tersebut menggunakan arduino agar dalam pengaliran air ke hidroganik tetap terjaga kebersihanya.

Sistem monitoring yang dapat memantau kualitas air saat ini telah menjadi kebutuhan yang sangat mendesak bagi area budidaya hidroganik. Hal ini disebabkan karena adanya catatan merugikan yang disebabkan oleh aktivitas bawah air dan kualitas air tidak terpantau secara realtime yang datang tiba-tiba mengakibatkan kerugian pada budidaya hidroganik. Dari tingginya kerugian yang ditimbulkan maka sistem yang dapat memantau kualitas air budidaya hidroganik sangat dibutuhkan oleh masyarakat, serta dengan adanya sistem pemantauan kualitas air budidaya hidroganik dapat diperoleh data-data yang akurat dengan mudah [1].

Perkembangan teknologi yang semakin canggih pada saat ini melahirkan sebuah produk analisa kualitas air budidaya hidroganik berbasis arduino. Berbagai aplikasi yang semodel dengan perangkat komputer dapat terinstal di dalamnya. Termasuk aplikasi dalam pemantauan kualitas air untuk dapat bekerja secara akurat[6].

Berdasarkan latar belakang di atas, maka peneliti tertarik untuk mengangkat judul "Monitoring Kualitas Air Pada Budidaya Hidroganik Berbasis Arduino" sehingga Informasi perubahan kualitas air dapat dibuat otomatis termonitor infonya ke LCD sehingga pengguna akan dapat mengetahui kualitas air tersebut. 


\section{Metode Penelitian}

Penelitian alat monitoring kualitas air pada budidaya hidroganik menggunakan pemograman arduino sangat penting dilakukan untuk mengeksekusi perintah yang dikehendaki pada rangkaian Arduino Uno. Saat hardware dimasukkan tegangan dalam hal ini catu daya, mikrokontroller akan memulai proses inisialisasi input maupun output serta variabel yang dibutuhkan. Data yang masuk ke dalam Arduino Uno selanjutnya diolah [2]. Bentuk flowchart dapat dilihat pada Gambar 1:

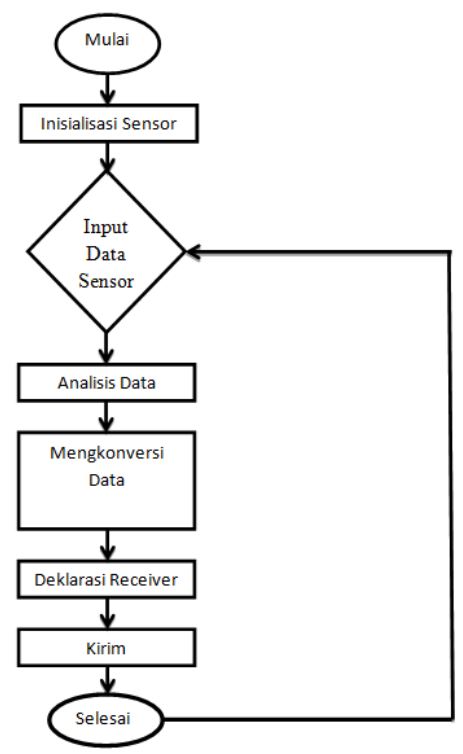

\section{Gambar 1. Ilustrasi Cara Kerja Sistem}

Dalam rencana penelitian ini menggunakan metode SDLC (System Development Life Cycle) dengan tahapan sebagai berikut [3] dapat dilihat pada gambar 2:

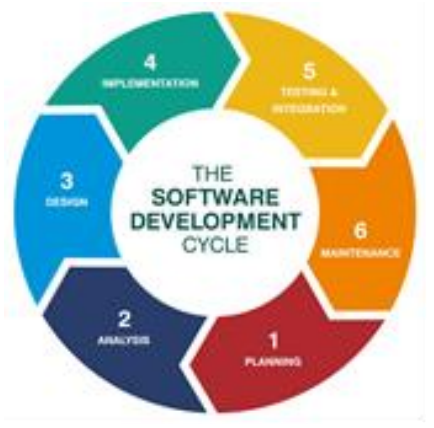

\section{Gambar 2. Model Waterfall SDLC}

\section{A. Planning (Perencanaan)}

Tahap ini adalah tahap penentuan halhal penting sebagai dasar dari permasalahan yang akan dianalisis. Dalam tahap ini dilakukan identifikasi masalah, pengumpulan data berupa studi literatur, wawancara dan observasi, menentukan kebutuhan sistem, mengevaluasi berbagai solusi alternatif dan melakukan verifikasi data.

B. Analysis (analisis)

Pada tahap ini ditentukan model data yang akan digunakan dan model proses yang akan diterapkan. Pada tahap ini juga nantinya akan ditelaah lebih lanjut

C. Design (Desain)

Tahap ini merupakan suatu proses menginventarisir dan mengubah kebutuhankebutuhan menjadi bentuk karakteristik yang dimengerti oleh perangkat lunak sebelum pembuatan alat.

D. Implementation (Implementasi)

Pada tahap implementasi kegiatan yang dilakukan adalah dengan menulis pengetahuan yang telah direpresentasikan (disandikan) dengan bahasa pemrograman, instalasi, demonstrasi dan penerapan sistem, orientasi pemakai, keamanan, dokumentasi dan integrasi.

E. Testing (Uji Coba)

Setelah tahapan implementasi selesai dikerjakan, tahap selanjutnya adalah dengan melakukan pengujian hasil implementasi, yaitu dengan melakukan pengujian terhadap kualitas air pada budidaya hidroganik.

F. Maintenance (Pemeliharaan)

Tahapan terakhir dalam sistem ini adalah melakukan pemeliharaan, diantaranya yaitu dengan memperbaiki desain dan error program dan menjaga sistem dari kemungkinan masalah di masa yang akan datang.

Pembuatan Alat Monitoring Kualitas Air Pada Budidaya Hidroganik ini terdiri dari perancangan software dan perancangan hardware. Perancangan software ini menggunakan Sofware Arduino Uno yang dapat dijalankan pada sistem operasi berbasis Mikrokontroler. Parameter yang di ukur adalah sensor suhu air, $\mathrm{pH}$ meter, sensor turbidity (kekeruhan), kemudian akan menampilkan informasi LED Indikator (Hijau: normal, Kuning: warning, Merah: bahaya) dan informasi menampilkan sensor suhu air, sensor $\mathrm{Ph}$ air, sensor kekeruhan melalui LCD 20x4.

Perancangan perangkat keras terdiri dari sistem kontrol yaitu Arduino yang bertugas sebagai pengendali sensor serta melakukan 
pengolahan data. Perancangan sistem dipresentasikan dalam bentuk blok diagram yang akan membantu dalam membuat perancangan alat "Pemantauan Kualitas Air Berbasis Arduino uno". Adapun penggunakan Arduino sebagai pengolah data, sensor $\mathrm{pH}$ air dan sensor suhu DS18B20 waterproof. Penelitian ini bekerja menggunakan Mikrokontroler Arduino dengan menggunakan catu daya yang dapat mengukur suhu, pH, Kekeruhan yang akan ditampilkan outputnya melalu LCD. Blok diagram alat Pemantauan Kualitas Air pada budidaya hidroganik berbasis Arduino Uno dapat dilihat pada Gambar 3:

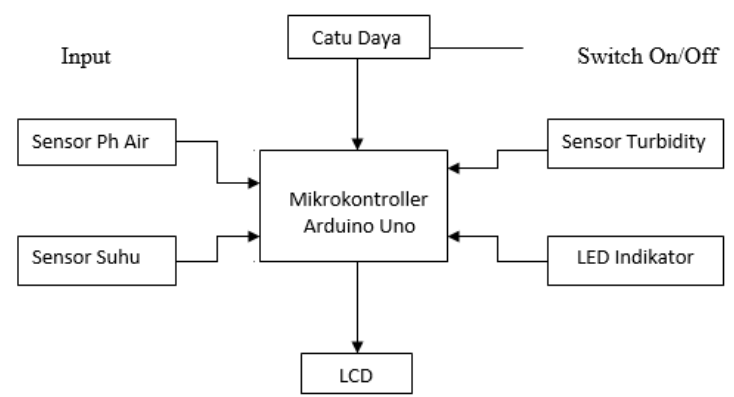

Gambar 3, Alat monitoring kualitas air pada budidaya hidroganik

\section{Hasil dan Pembahasan}

Perakitan perangkat keras merupakan proses dalam menghubungkan semua perangkat sehingga dapat membaca nilai sensor sampai memicu kinerja perangkat output Gambar 2 di bawah ini menunjukan rangkaian skematik dari sistem yang akan dibuat dapat dilihat pada Gambar 4:.

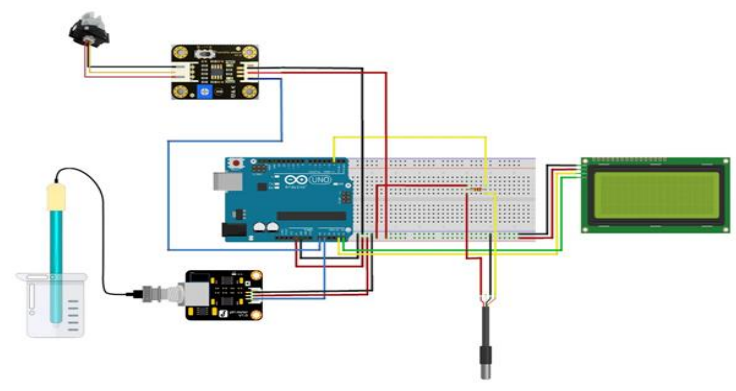

Gambar 4. Rangkaian Skematik keseluruhan Sistem

Proses Perakitan alat monitoring kualitas air pada budidaya hidroganik untuk memenuhui pengendalian objek dapat dilihat pada Gambar 5:

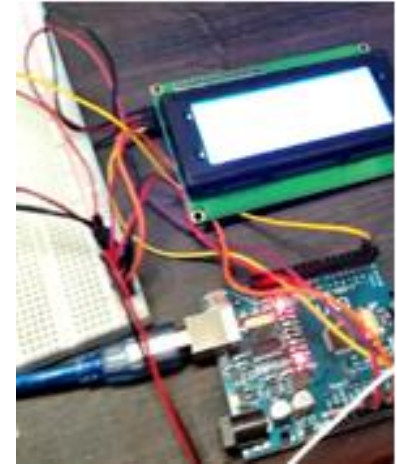

Gambar 5. Proses Perakitan Alat Monitoring Kualitas Air Pada Budidaya Hidroganik

Instalasi perangkat keras merupakan suatu proses instalasi alat ataupun perakitan alat yang digunakan dalam membangun Alat Monitoring Kualitas Air Pada Budidaya Hidroganik. Adapun Instalasi perangkat alat monitoring kualitas air pada budidaya hidroganik dapat dilihat pada gambar 6:

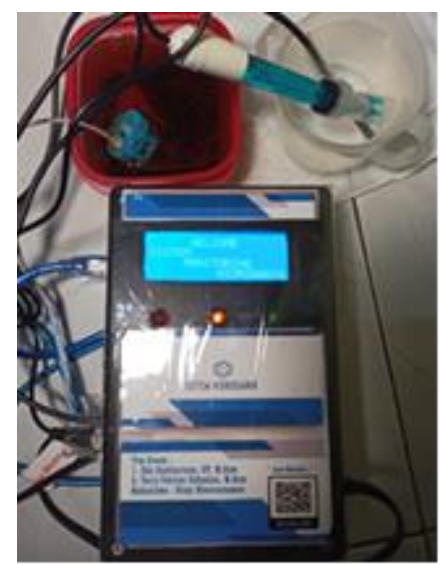

Gambar 6. Instalasi Perangkat Alat Monitoring Kualitas Air Pada Budidaya Hidroganik.

Tampilan digital sebagai pengendali utama dalam pengiriman teks pada LCD display, dimana teks yang dikirim akan ditampilkan pada Modul LCD. Sebelum pengiriman pastikan port sudah terdeteksi. Adapun hasil dari perakitan alat monitoring kualitas air pada budidaya hidroganik, perangkat keras yang digunakan untuk memenuhui pengendalian objek dapat dilihat pada gambar 7: 


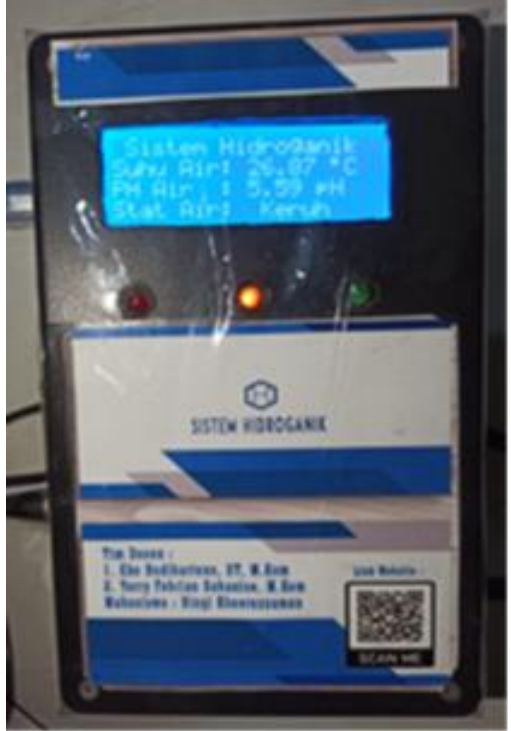

Gambar 7. Tampilan LCD Alat Monitoring

Kualitas Air Pada Budidaya Hidroganik

Untuk menemukan apakah perangkat lunak sudah berjalan sesuai dengan semestinya, tidak memiliki masalah eror dan sesuai apa yang diharapkan. Pengujian mengunakan Metode BlackBox. Metode ini digunakan untuk mengetahui apakah perangkat lunak berfungsi dengan benar, perancangan data uji yang di dasarkan pada spesifikasi perangkat lunak yang dibuat dapat dilihat pada tabel 1 :

Tabel 1. Pengujian Alat

\begin{tabular}{|c|l|c|l|c|}
\hline No. & \multicolumn{1}{|c|}{$\begin{array}{c}\text { Input } \\
\text { Pengujian }\end{array}$} & $\begin{array}{l}\text { Fungsi } \\
\text { Sensor }\end{array}$ & $\begin{array}{l}\text { Hasil Yang } \\
\text { Diharapka } \\
\text { n }\end{array}$ & $\begin{array}{c}\text { Hasil } \\
\text { Uji }\end{array}$ \\
\hline 1 & $\begin{array}{l}\text { Melakukan } \\
\text { pengujian } \\
\text { LCD }\end{array}$ & Aktif & $\begin{array}{l}\text { LCD aktif } \\
\text { terbaca } \\
\text { tulisan dan } \\
\text { huruf }\end{array}$ & $\begin{array}{l}\text { Memen } \\
\text { uhi/Ok }\end{array}$ \\
\hline 2 & $\begin{array}{l}\text { Melakukan } \\
\text { pengujian } \\
\text { Suhu }\end{array}$ & Aktif & $\begin{array}{l}\text { Sensor } \\
\text { mendekteks } \\
\text { i suhu air }\end{array}$ & $\begin{array}{l}\text { Memen } \\
\text { uhi/Ok }\end{array}$ \\
\hline 3 & $\begin{array}{l}\text { Melakukan } \\
\text { pengujian pH } \\
\text { Air }\end{array}$ & Aktif & $\begin{array}{l}\text { Diharapkan } \\
\text { sensor } \\
\text { mendeteksi } \\
\text { pH air }\end{array}$ & $\begin{array}{l}\text { Memen } \\
\text { uhi/Ok }\end{array}$ \\
\hline 4 & $\begin{array}{l}\text { Melakukan } \\
\text { pengujian } \\
\text { Kekeruhan }\end{array}$ & Aktif & $\begin{array}{l}\text { Diharapkan } \\
\text { sensor } \\
\text { mendeteksi } \\
\text { kekeruhan }\end{array}$ & $\begin{array}{l}\text { Memen } \\
\text { uhi/Ok }\end{array}$ \\
\hline
\end{tabular}

Data hasil pengujian yang telah dilakukan terhadap kinerja Alat tersebut menunjukkan bahwa Alat dapat bekerja dengan baik, mudah digunakan dan lebih efisien karena Alat ini hanya membutuhkan catu daya untuk menampilkan di layar LCD dan mempermudah proses pengukuran suhu air, pH air, dan kekeruhan air (turbidity) sehingga di harapkan dapat membantu masyarakat dalam budidaya hidroganik supaya hasil yang didapat lebih baik.

\section{Kesimpulan}

Berdasarkan hasil penelitian yang telah dijelaskan sebelumnya, maka dapat diambil kesimpulan sebagai berikut:

1. Pembuatan Alat Monitoring Kualitas Air Pada Budidaya Hidroganik dapat mempermudah proses pengukuran kualitas air (suhu air, $\mathrm{pH}$ air, kekeruhan) bekerja secara otomatis dan alat ini hanya membutuhkan catu daya.

2. Penelitian ini sangat berguna bagi masyarakat dalam budidaya hidroganik didalam memonitoring kualitas air sehingga hasil yang didapatkan lebih maksimal dalam budidaya sayur-sayuran dan budidaya ikan.

3. Penelitian ini sangat berguna bagi masyarakat dalam budidaya hidroganik di dalam memonitoring kualitas air sehingga hasil yang didapatkan lebih maksimal dalam budidaya hidroganik (sayur-sayuran dan ikan).

\section{Daftar Pustaka}

[1] ANANG MASDUKI, 2017. Hidroponik Sebagai Sarana Pemanfaatan Lahan Sempit di Dusun Randubelang, Bangunharjp, Sewon, Bantul.

[2] DJUANDI, FERI. 2011. Pengenalan Arduino.E-book, www. Tobuku.

[3] DARI, WULAN. 2015. Penerapan Metode System Development Life Cycle Pada Pembuatan Sistem Informasi Penjualan Produk Batik Kurowo Jakarta 3(2): 222-28.

[4] EKO BUDIHARTONO, IDA AFRILIANA, 2020. Monitoring Ketinggian Plateau Berbasis Mikrokontroler Menggunakan Atmega 328 Dan Sensor Altimeter.

[5] KARINA, NADIA Al, 2017. Perancangan Sistem Alir Larutan Nutrisi Otomatis pada Tanaman Hidroponik dengan Mikrokontroler Arduino Uno Berbasis Android.

[6] M. AKSA, JAMALUDDIN P, SUBARIYANTO, 2019. Rekayasa Media Tanam Pada Sistem Penanaman Hidroponik Untuk Meningkatkan Pertumbuhan Tanaman Sayuran.

[7] MARPAUNG, NOVERY LYSBETTI, EDY ERVIANTO, 2012. Data logger sensor suhu berbasis mikrokontroler atmega 8535 dengan PC sebagai tampilan, Jurnal Ilmiah Elite Elektro. 